\title{
The effects of halogen elements on the opening of an icosahedral $B_{12}$ framework
}

Liang-Fa Gong, Wei Li, Edison Osorio, Xin-Min Wu, Thomas Heine, and Lei Liu

Citation: J. Chem. Phys. 147, 144302 (2017); doi: 10.1063/1.4998948

View online: https://doi.org/10.1063/1.4998948

View Table of Contents: http://aip.scitation.org/toc/jcp/147/14

Published by the American Institute of Physics

\section{Articles you may be interested in}

An intrinsic representation of atomic structure: From clusters to periodic systems

The Journal of Chemical Physics 147, 144106 (2017); 10.1063/1.4997292

Density-functional thermochemistry. III. The role of exact exchange

The Journal of Chemical Physics 98, 5648 (1993); 10.1063/1.464913

Distance-including rigorous upper bounds and tight estimates for two-electron integrals over long- and shortrange operators

The Journal of Chemical Physics 147, 144101 (2017); 10.1063/1.4994190

2D IR spectroscopy of high-pressure phases of ice

The Journal of Chemical Physics 147, 144501 (2017); 10.1063/1.4993952

Toward reliable density functional methods without adjustable parameters: The PBE0 model

The Journal of Chemical Physics 110, 6158 (1999); 10.1063/1.478522

Self-consistent molecular orbital methods. XX. A basis set for correlated wave functions

The Journal of Chemical Physics 72, 650 (1980); 10.1063/1.438955

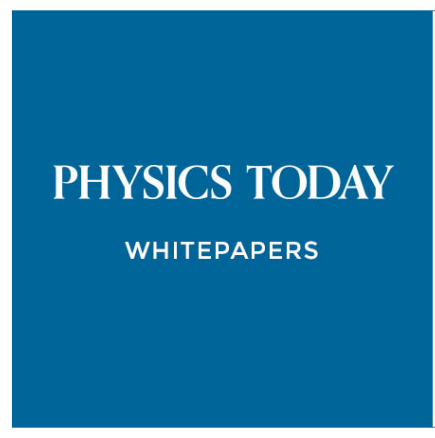

ADVANCED LIGHT CURE ADHESIVES

Take a closer look at what these environmentally friendly adhesive systems can do

\section{READ NOW}

PRESENTED BY

Q.MASTERBOND 


\title{
The effects of halogen elements on the opening of an icosahedral $B_{12}$ framework
}

\author{
Liang-Fa Gong, ${ }^{1}$ Wei Li, ${ }^{1}$ Edison Osorio, ${ }^{2}$ Xin-Min Wu, ${ }^{1}$ Thomas Heine, ${ }^{3,4}$ and Lei Liu ${ }^{4, a)}$ \\ ${ }^{1}$ National Demonstration Center of Chemistry and Chemical Engineering Experimental Teaching, \\ School of Chemical Engineering, Beijing Institute of Petrochemical Technology, Beijing 102617, China \\ ${ }^{2}$ Departamento de Ciencias Básicas, Fundación Universitaria Luis Amigó, SISCO, \\ Transversal 51A \# 67B 90, Medellín, Colombia \\ ${ }^{3}$ Wilhelm-Ostwald-Institut für Physikalische und Theoretische Chemie, Universität Leipzig, \\ Linnéstr. 2, 04103 Leipzig, Germany \\ ${ }^{4}$ Department of Physics and Earth Sciences, Jacobs University Bremen, Campus Ring 1, 28759 Bremen, Germany
}

(Received 3 August 2017; accepted 25 September 2017; published online 10 October 2017)

\begin{abstract}
The fully halogenated or hydrogenated $\mathrm{B}_{12} \mathrm{X}_{12}{ }^{2-}(\mathrm{X}=\mathrm{H}, \mathrm{F}, \mathrm{Cl}, \mathrm{Br}$ and I) clusters are confirmed to be icosahedral. On the other hand, the bare $\mathrm{B}_{12}$ cluster is shown to have a planar structure. A previous study showed that a transformation from an icosahedron to a plane happens when 5 to 7 iodine atoms are remained [P. Farràs et al., Chem. - Eur. J. 18, 13208-13212 (2012)]. Later, the transition was confirmed to be seven iodine atoms based on an infrared spectroscopy study [M. R. Fagiania et al., Chem. Phys. Lett. 625, 48-52 (2015)]. In this study, we investigated the effects of different halogen atoms on the opening of the $\mathrm{B}_{12}$ icosahedral cage by means of density functional theory calculations. We found that the halogen elements do not have significant effects on the geometries of the clusters. The computed infrared (IR) spectra show similar representative peaks for all halogen doped clusters. Interestingly, we found a blue-shift in the IR spectra with the increase in the mass of the halogen atoms. Further, we compared the Gibbs free energies at different temperatures for different halogen atoms. The results show that the Gibbs free energy differences between open and close structures of $\mathrm{B}_{12} \mathrm{X}_{7}^{-}$become larger when heavier halogen atoms are presented. This interesting finding was subsequently investigated by the energy decomposition analysis. Published by AIP Publishing. https://doi.org/10.1063/1.4998948
\end{abstract}

\section{INTRODUCTION}

Together with other elements, boron exists in different forms of compounds. Examples of these compounds are boranes (or borohydrides), ${ }^{1}$ carboranes, ${ }^{2}$ and metallacarboranes. ${ }^{3}$ Their peculiar electronic structures and unusual chemical bonds result in a variety of interesting applications in the field of medicine ${ }^{4}$ and in the production of coordination polymers, ${ }^{5}$ liquid crystals, ${ }^{6}$ ionic liquids, ${ }^{7}$ and luminescent materials. ${ }^{8}$ Typically, boron compounds show threedimensional (3D) deltahedra structures with multiple B-B bonds (i.e., multiple-center two-electron bonds). ${ }^{9-11}$ Among them, a heavily studied example is the fully iodine or hydrogen doped $\mathrm{B}_{12} \mathrm{I}_{12}{ }^{2-}$ or $\mathrm{B}_{12} \mathrm{H}_{12}{ }^{2-}$ cluster. ${ }^{12}$ These clusters have been confirmed to be icosahedral (a central icosahedral $\mathrm{B}_{12}$ cage with a dopant in the periphery). Like carbon atoms, boron itself can also form atomic clusters, say boron clusters. Unlike boron compounds in deltahedra structures, small pure boron clusters without further dopants are essentially planar. ${ }^{13-15}$ Until now, the biggest pure boron cluster that was confirmed to be planar is the $\mathrm{B}_{40}{ }^{-}$cluster, of which the global minimum structure is a planar structure with two adjacent hexagonal holes. ${ }^{16}$ Note that many planar boron clusters have hexagonal holes in their most stable structures,

a)Current address: Max Planck Institute for Polymer Research, Ackermannweg 10, 55128 Mainz, Germany. E-mail: liulei3039@gmail.com and the smallest one with hexagonal vacancy was recently confirmed to be $\mathrm{B}_{26} \cdot{ }^{-17}$ Based on the theoretical analysis, these geometric characteristics were attributed for their high stability. ${ }^{18}$

An interesting question is at how many dopants the icosahedral $\mathrm{B}_{12}$ cage opens when a fully saturated $\mathrm{B}_{12} \mathrm{I}_{12}{ }^{2-}$ cluster undergoes a step by step stripping of the iodine atoms. Previously, a complete series of partly iodinated $\mathrm{B}_{12} \mathrm{I}_{\mathrm{n}}{ }^{\mathrm{x}-}$ (with $n$ $=1$ to $12, x=1$ or 2 ) was successfully generated in the gasphase and was studied by mass spectroscopy. ${ }^{19}$ Together with theoretical calculations, it was shown that the most stable structures for $n \geq 8$ remained in the icosahedral $\mathrm{B}_{12}$ cages. The planar structures are preferred for $n \leq 4$. The transition between the icosahedral and planar structures is found be $n=5$ to 7 depending on the temperatures. ${ }^{9}$ Later, a combined experimental and theoretical infrared (IR) spectroscopy study was carried out to narrow down the region of transition. ${ }^{20}$ The results showed that the simulated IR spectra matches the experimental IR spectra based on the icosahedral structures for $n \geq 8$. The simulated IR spectra of the open- $\mathrm{B}_{12} \mathrm{I}_{7}^{-}$cluster showed a certain degree of correspondence to the experimental IR spectra. These results indicated that the icosahedral $B_{12}$ cage opens at $\mathrm{B}_{12} \mathrm{I}_{7}^{-}$and most probably the experimentally obtained $\mathrm{B}_{12} \mathrm{I}_{7}^{-}$clusters are a mixture of low-lying isomers of both close and open structures. The 3D-2D transition was also found in the case of $\mathrm{B}_{6} \mathrm{H}_{\mathrm{n}}{ }^{-}$clusters upon dehydrogenation. ${ }^{21}$ Based on the chemical bonding analysis, the authors 
concluded that planar structures become less stable for $n \geq 4$ because the doped hydrogen atom destroys the $2 c-2 e$ B-B $\sigma$-bonding pattern in the periphery.

Until now, all studies are based on the iodine atoms. To the best of our knowledge, there is no previous study investigating the effects of the different halogen atoms on the opening of the icosahedral $\mathrm{B}_{12}$ cage. To this end, we performed density functional theory (DFT) calculations in this study. We first investigated the effects on the geometries and the IR spectra by changing the substitutions from fluorine $(\mathrm{F})$, chlorine $(\mathrm{Cl})$, and bromine $(\mathrm{Br})$ to iodine (I). Subsequently, we computed the Gibbs free energy difference $(\Delta G)$ between the close- and open- $\mathrm{B}_{12} \mathrm{X}_{7}{ }^{-}$clusters $(\mathrm{X}=\mathrm{F}, \mathrm{Cl}, \mathrm{Br}$, and $\mathrm{I})$, and the electronic energy $(\Delta E)$ contributions are studied by the energy decompositions analysis (EDA).

\section{COMPUTATIONAL DETAILS}

All DFT calculations were carried out with the Gaussian 09 package. $^{22}$ All structures were fully optimized at the PBE0 level of theory, ${ }^{23}$ with the basis set of def2-TZVP. ${ }^{24}$ Within the calculations, the effective core basis set of LanL2DZ was assigned for the iodine atom. ${ }^{25}$ The harmonic frequency calculations were performed at the same level of theory to characterize the nature of stationary points, i.e., no imaginary frequencies were found for all optimized structures. The initial structures were taken from previous studies by replacing I with $\mathrm{F}, \mathrm{Cl}$, and $\mathrm{Br} .{ }^{9,20}$ The PBE0 functional was benchmarked as a reliable DFT method for boron systems in terms of both geometries and energetics. ${ }^{25}$ The combination of a PBE0 functional with a def2-TZVP basis set has been widely used to study the electronic structures of boron clusters. ${ }^{11,18,26}$ The bonding interactions corresponding to the formation of closeand open- $\mathrm{B}_{12} \mathrm{X}_{7}{ }^{-}$have been analyzed with the EDA scheme. ${ }^{27}$ These calculations were performed at the PBE0 level with the basis set of TZ2P. ${ }^{28}$ The scalar relativistic effects for the iodine atom were incorporated by the zeroth order regular approximation (ZORA). ${ }^{29}$ All EDA calculations were performed by employing ADF software. ${ }^{30}$

\section{RESULTS AND DISCUSSIONS}

All optimized structures, $\mathrm{B}_{12} \mathrm{X}_{12}{ }^{2-}$, close $-\mathrm{B}_{12} \mathrm{X}_{7}^{-}$, open$\mathrm{B}_{12} \mathrm{X}_{7}^{-}$, and bare $\mathrm{B}_{12}$ clusters, are depicted in Fig. 1, and the selected distances are provided in Tables S1-S3 of the supplementary material. The most stable structures of $\mathrm{B}_{12} \mathrm{X}_{12}{ }^{2-}$ show icosahedral configurations and have the symmetry of $I_{\mathrm{h}}$. In these structures, all B-B bond lengths are the same $(\sim 1.80 \AA)$, indicating almost no effects of different halogen atoms on the geometry of the icosahedral $\mathrm{B}_{12}$ cage. The $\mathrm{B}-\mathrm{X}$ bond lengths gradually increase from $1.38 \AA\left(\mathrm{B}_{12} \mathrm{~F}_{12}{ }^{2-}\right)$ to $2.18 \AA\left(\mathrm{B}_{12} \mathrm{I}_{12}{ }^{2-}\right)$, which is in the same order to the van der Waals atomic radius of halogen atoms. The bare $\mathrm{B}_{12}$ cluster without any halogen elements has a $C_{3 v}$ symmetry, and the $\mathrm{B}-\mathrm{B}$ bond length can be categorized into three groups: (1) shortest B-B bond length of about $1.55 \AA$ for B6 and B7; (2) medium B-B bond length about 1.60 for B7-B4, B7-B5, and $\mathrm{B} 12-\mathrm{B} 5$; and (3) longest $\mathrm{B}-\mathrm{B}$ bond length for B4-B5, which is about $1.80 \AA$. The close structures of $\mathrm{B}_{12} \mathrm{X}_{7}{ }^{-}$overall remain in the icosahedral $B_{12}$ framework but with some changes in the $\mathrm{B}-\mathrm{B}$ bond length distributions. For example, the bond lengths of B1-B2 and B1-B4(B5) are 1.60 and $1.67 \AA$, respectively. The bond lengths between B2 and B4 (B6), B3 and B4, and $\mathrm{B} 5$ and $\mathrm{B} 6$ are $1.75 \AA$, while the bond length for B4-B5 is only

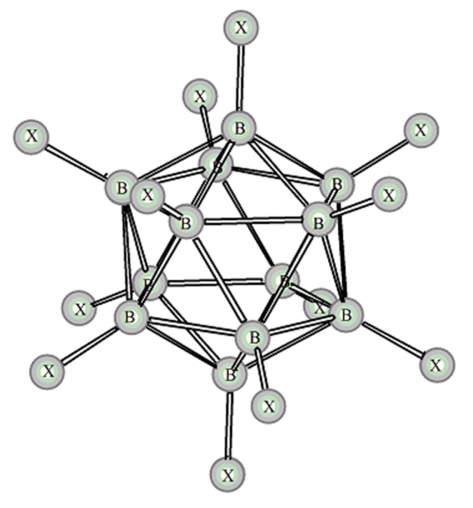

a

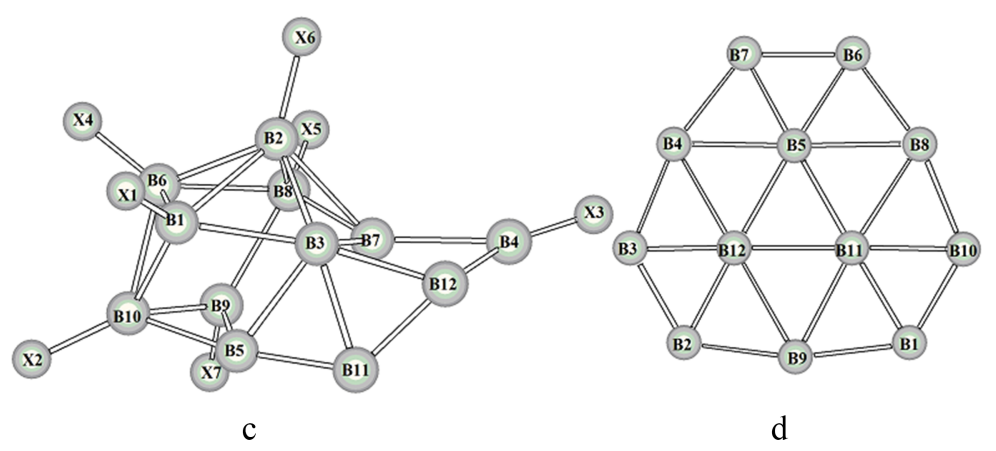

FIG. 1. The most stable structures of $\mathrm{B}_{12} \mathrm{X}_{12}{ }^{2-}$ (a: $\left.I_{\mathrm{h}}\right)$, close $-\mathrm{B}_{12} \mathrm{X}_{7}^{-}\left(\mathrm{b}: C_{s}\right)$, open $-\mathrm{B}_{12} \mathrm{X}_{7}^{-}\left(\mathrm{c}: C_{1}\right)$, and $\mathrm{B}_{12}(\mathrm{~d}$ : $C_{3 v}$ ) clusters $(\mathrm{X}=\mathrm{F}, \mathrm{Cl}, \mathrm{Br}$, and $\mathrm{I})$. 
$1.58 \AA$ A. In general, the B-B bond lengths in the lower part of the $\mathrm{B}_{12} \mathrm{X}_{7}^{-}$clusters [Fig. 1(b)] are longer than the upper part. For example, the bond length of B10-B12 is $1.74 \AA$, and bond lengths of B7(B8)-B12 and B9(B11)-B12 are more than $1.80 \AA$. This might be the consequence of the Pauli repulsion between the halogen atoms and there are more halogen atoms in the lower part than the upper part (five halogen atoms in the lower part while only two in the upper part). Note that we do not find significant effects of the different halogen atoms on the $\mathrm{B}-\mathrm{B}$ bond length distributions, and all close $-\mathrm{B}_{12} \mathrm{X}_{7}^{-}$clusters show similar B-B bond lengths (for more details, see Table S1 of the supplementary material). The most stable open structures of $\mathrm{B}_{12} \mathrm{X}_{7}{ }^{-}$are very complicated as shown in Fig. 1(c). In general, they show both features of the icosahedral $\mathrm{B}_{12} \mathrm{X}_{12}{ }^{2-}$ and the bare $\mathrm{B}_{12}$ clusters, for example, structures with a vertex boron atom (i.e., B2) surrounding five boron atoms, similar to that in the icosahedral $\mathrm{B}_{12} \mathrm{X}_{12}{ }^{2-}$ cluster. On the other hand, there are also boron atoms located on the periphery similar to a bare $\mathrm{B}_{12}$ cluster, such as B11 and B12. The bond lengths between the vertex B2 atom and its neighbors are about $1.80 \AA$, which is again similar to the vertex boron atoms in the icosahedral $\mathrm{B}_{12} \mathrm{X}_{12}{ }^{2-}$ clusters. The bond lengths between the boron atoms on the periphery vary from 1.6 to $2.0 \AA$. For example, the bond length of B11-B12, in which there are no halogen substitutions, is only $1.58 \AA$. However, the bond length of B5-B9 is more than $2.0 \AA$.

It was previously shown that the open and close structures have different features in the IR spectra. ${ }^{20}$ For example, the close (or icosahedral) structures often show adsorption peaks below $1000 \mathrm{~cm}^{-1}$ and the overall IR profile is quite simple. The open structures often have higher energy absorptions between 1000 and $1300 \mathrm{~cm}^{-1}$, and the overall IR profiles are rather complicated. To find out the effects of different halogen atoms on the IR spectra, we performed the IR analysis on both the close and open structures of $\mathrm{B}_{12} \mathrm{X}_{7}^{-}$, and results are shown in Fig. 2 . In the cases of close $-\mathrm{B}_{12} \mathrm{X}_{7}^{-}$, we found two representative peaks, $\mathrm{A}^{\prime}$ and $\mathrm{A}^{\prime \prime}$. The peak $\mathrm{A}^{\prime}$ corresponds to the deformation motion of the icosahedral $\mathrm{B}_{12}$ cage involving the asymmetrical stretching mode of the $\mathrm{B}-\mathrm{X}$ bonds. The second one, peak $\mathrm{A}^{\prime \prime}$, corresponds to the breaking motion of the icosahedral $\mathrm{B}_{12}$ cage involving the symmetrical stretching mode of the $\mathrm{B}-\mathrm{X}$ bonds. Note that the IR spectra of the close structures of $\mathrm{B}_{12} \mathrm{X}_{7}^{-}$are generally similar to those of the icosahedral $\mathrm{B}_{12} \mathrm{I}_{12}{ }^{2-}$ cluster, indicating that the icosahedral $\mathrm{B}_{12}$ cage remains intact after the removal of five halogen atoms. This has been also shown by the geometric parameters of the icosahedral $\mathrm{B}_{12} \mathrm{I}_{12}{ }^{2-}$ and close$\mathrm{B}_{12} \mathrm{X}_{7}^{-}$clusters, in which the $\mathrm{B}-\mathrm{B}$ bond lengths are rather close to each other. Interestingly, we found that the positions of the same peaks ( $\mathrm{A}^{\prime}$ and $\mathrm{A}^{\prime \prime}$ ) shift gradually to lower wavenumbers (blue-shift) when the halogen atoms are changed from $\mathrm{F}$ to I. For example, the peak $\mathrm{A}^{\prime}$ of the close $-\mathrm{B}_{12} \mathrm{~F}_{7}{ }^{-}$cluster located at about $800 \mathrm{~cm}^{-1}$ decreases to $680 \mathrm{~cm}^{-1}$ when we replaced F by I, while the peak $\mathrm{A}^{\prime \prime}$ shifts correspondingly from 1250 to $1000 \mathrm{~cm}^{-1}$. The spectra of the open $-\mathrm{B}_{12} \mathrm{X}_{7}^{-}$cluster generally are complicated and different compared with those of the icosahedral $\mathrm{B}_{12} \mathrm{I}_{12}{ }^{2-}$ and close $-\mathrm{B}_{12} \mathrm{X}_{7}{ }^{-}$clusters. This is most likely attributed to complex structures of the open forms: low symmetry and different boron coordination. To simplify the discussion, we classified the peaks into two groups, $\mathrm{B}^{\prime}$ and $\mathrm{B}^{\prime \prime}$ (Fig. 2). The group $\mathrm{B}^{\prime}$ consists mainly of the B-B stretching mode of the icosahedral-like boron atoms, $\mathrm{B} 2$ and its neighbors [i.e., B1, B3, B6, B7, and B8 in Fig. 1(c)]. The second group, peaks B", refers essentially to the B-B stretching mode of the boron atoms on the periphery such as B11, B12, and B5 in Fig. 1(c). Similar to that of the close $-\mathrm{B}_{12} \mathrm{X}_{7}^{-}$cluster, the positions of the peaks in the case of open- $\mathrm{B}_{12} \mathrm{X}_{7}^{-}$clusters also shift to the lower wavenumbers when we changed the halogen atom from $\mathrm{F}$ to $\mathrm{I}$. The largest shift found is for the peaks $\mathrm{B}^{\prime}$ of $\mathrm{B}_{12} \mathrm{I}_{7}^{-}$which is about $200 \mathrm{~cm}^{-1}$. However, we have not found obvious shift of peaks $\mathrm{B}^{\prime \prime}$. This is because the motions of these peaks do not involve halogen atoms while peaks $\mathrm{A}^{\prime}, \mathrm{A}^{\prime \prime}$, and $\mathrm{B}^{\prime}$ do have contributions from $\mathrm{B}-\mathrm{X}$ stretching. When we change the substitutions, the average mass of the groups (i.e., B-X bonds) changes as well. As such, we found the shift in the wavenumbers for such bonds in the IR spectra.

The reactivity of the halogenated boron clusters (i.e., $\mathrm{B}_{12} \mathrm{X}_{12}{ }^{2-}$ ) is often studied by the electrospray ionization mass spectrometry (ESI-MS). ${ }^{19}$ The ions produced by ESI-MS often can capture internal energy in the range of $100-200 \mathrm{~kJ} \mathrm{~mol}^{-1}$, which corresponds to the temperature of several thousands Kelvin. Therefore, we computed the Gibbs free energies, $\Delta G$, for both open- and close- $\mathrm{B}_{12} \mathrm{X}_{7}^{-}$at 300,1500 , and $5000 \mathrm{~K}$, through the harmonic approximations for the minimum structures on the potential energy surface at $0 \mathrm{~K}$. The Gibbs free energies were computed by $\Delta G=G_{\text {ico }}-G_{\text {ope }}=\Delta U+\mathrm{R} T$

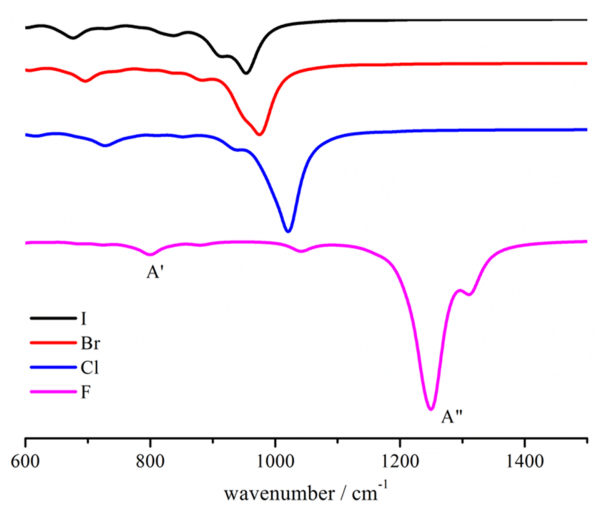

a

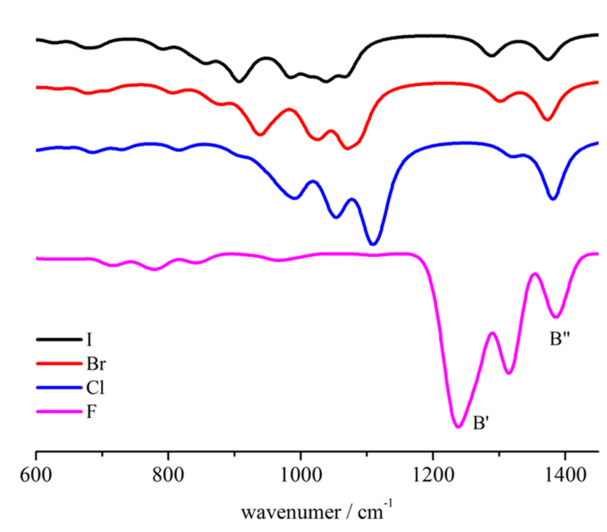

b
FIG. 2. Simulated IR spectrum of close- (a) and open- (b) $\mathrm{B}_{12} \mathrm{X}_{7}^{-}$at the PBE0/def2-TZVP (LanL2DZ for I) level of theory. $\mathrm{X}=\mathrm{F}, \mathrm{Cl}, \mathrm{Br}$, and $\mathrm{I}$. 
TABLE I. Calculated Gibbs free energy difference between open- and close$\mathrm{B}_{12} \mathrm{X}_{7}^{-}$at the PBE0/def2-TZVP (LanL2DZ for I) level of theory. All values are given in $\mathrm{kcal} \mathrm{mol}^{-1}$.

\begin{tabular}{lrrrr}
\hline \hline & $\mathrm{B}_{12} \mathrm{~F}_{7}^{-}$ & $\mathrm{B}_{12} \mathrm{Cl}_{7}^{-}$ & $\mathrm{B}_{12} \mathrm{Br}_{7}^{-}$ & $\mathrm{B}_{12} \mathrm{I}_{7}^{-}$ \\
\hline $0 \mathrm{~K}$ & 22.3 & 16.2 & 14.8 & 12.2 \\
$300 \mathrm{~K}$ & 17.8 & 11.8 & 10.4 & 7.8 \\
$1500 \mathrm{~K}$ & 1.9 & -4.2 & -5.8 & -8.2 \\
$5000 \mathrm{~K}$ & -45.5 & -51.9 & -53.8 & -55.6 \\
\hline \hline
\end{tabular}

$-T \Delta S$ ( $U$ is the internal energy, $T$ is the temperature, $R$ is the gas constant, and $S$ is the entropy), and the data are given in Table I. Previously, it was found that for the $\mathrm{B}_{12}$ cluster with seven iodine atoms, the temperature dependence of $\Delta G$ is important, ${ }^{9}$ and here we have found the same phenomenon. For example, at 0 and $300 \mathrm{~K}$, the close- $\mathrm{B}_{12} \mathrm{I}_{7}^{-}$cluster is favored by 22.3 and $7.8 \mathrm{kcal} \mathrm{mol}^{-1}$, respectively, indicating that the $\mathrm{B}_{12} \mathrm{I}_{7}^{-}$cluster has an icosahedral configuration at low temperatures, i.e., in the solid state. However, at 1500 and $5000 \mathrm{~K}$, the open- $\mathrm{B}_{12} \mathrm{I}_{7}-$ cluster is favored by 8.2 and $55.6 \mathrm{kcal} \mathrm{mol}^{-1}$, respectively, indicating that the icosahedral $\mathrm{B}_{12}$ cage opens at $\mathrm{B}_{12} \mathrm{I}_{7}^{-}$in the gas-phase. This general trend applies to all halogenated $\mathrm{B}_{12} \mathrm{X}_{7}^{-}$clusters. At low temperatures, the close form of $\mathrm{B}_{12} \mathrm{X}_{7}^{-}$is favored while open forms become dominant when the temperature increases to 1500 and $5000 \mathrm{~K}$. As pointed out by the previous study, at higher temperatures, the open structures are favored by the entropy contributions. ${ }^{9}$ The important finding in this study is the $\Delta G$ values for different halogen atoms. Let us take the values at $1500 \mathrm{~K}$ as an example since this temperature is more realistic considering the thermal energy of the ions in ESI-MS. For $\mathrm{B}_{12} \mathrm{~F}_{7}^{-}$, $\Delta G$ is $1.9 \mathrm{kcal} \mathrm{mol}^{-1}$. This positive value indicates that the close structure is slightly favored over the open structure when $\mathrm{B}_{12}$ is doped by seven fluorine atoms. Taking the error of the DFT method into account, we see that $\mathrm{B}_{12} \mathrm{~F}_{7}{ }^{-}$might distribute equally as open and close structures in the gap-phase at $1500 \mathrm{~K}$. In other words, to completely break the icosahedral $\mathrm{B}_{12}$ cage of $\mathrm{B}_{12} \mathrm{~F}_{7}^{-}$or to have higher concentration of the open structures, we need a temperature higher than $1500 \mathrm{~K}$ or let the clusters stay for a longer time in the iron trap of ESIMS. For $\mathrm{B}_{12} \mathrm{Cl}_{7}^{-}$and $\mathrm{B}_{12} \mathrm{Br}_{7}^{-}, \Delta G$ is about $-5.0 \mathrm{kcal} \mathrm{mol}^{-1}$. These larger negative values indicate that a higher concentration of the open structures would be obtained in the gas-phase in the cases of $\mathrm{Cl}$ and $\mathrm{Br} . \Delta G$ became even more negative in the case of $\mathrm{B}_{12} \mathrm{I}_{7}^{-}$, which is $-8.2 \mathrm{kcal} \mathrm{mol}^{-1}$. This reveals that the open forms of the $\mathrm{B}_{12} \mathrm{I}_{7}^{-}$cluster are dominant over the close forms at $1500 \mathrm{~K}$. In short, the heavier the halogen atoms presented in the $\mathrm{B}_{12} \mathrm{X}_{7}^{-}$cluster, the lower the temperature needed to open the icosahedral $\mathrm{B}_{12}$ cage. This is most probably because of the pulling manner of halogen atoms in the breaking of B-B bonds. Heavier elements have stronger strength to pull the boron atoms and it is easier to break the B-B bonds.

In general, the open forms of the $\mathrm{B}_{12} \mathrm{X}_{7}^{-}$cluster became more stable over the close forms from $\mathrm{F}$ to I (Table I). At 0 and $300 \mathrm{~K}$, all $\Delta G$ values were positive, indicating that the close forms of $\mathrm{B}_{12} \mathrm{X}_{7}^{-}$are favored for all halogen atoms. However, the $\Delta G$ values show similar trend to that computed at higher temperatures, i.e., 1500 and $5000 \mathrm{~K}$. Interestingly, the difference in $\Delta G$ values are almost constant and are independent from the temperatures. Taking $\mathrm{B}_{12} \mathrm{Br}_{7}{ }^{-}$and $\mathrm{B}_{12} \mathrm{I}_{7}^{-}$as examples, we observe that the differences between $\Delta G$ are about $3 \mathrm{kcal} \mathrm{mol}^{-1}$ from 0 to $5000 \mathrm{~K}$ (the difference between the last two columns in Table I). This finding indicates that the decrease in the $\Delta G$ values is most likely due to the electronic energy component, instead of the thermal or entropy contributions. Thus, we performed EDA calculations on the ground of electronic energies, $\Delta E(\Delta G$ at $0 \mathrm{~K})$, to study the effects of different halogen atoms on the relative stability between the open and close forms of $\mathrm{B}_{12} \mathrm{X}_{7}{ }^{-}$. The total electronic energies and their individual contributions of $\mathrm{B}_{12} \mathrm{X}_{7}^{-}$are summarized in Table II. The calculated intrinsic interaction energies $\left(E_{\text {total }}\right)$ have large negative values, which indicate strong attractions of B-B and B-X pairs. It can be seen that the largest value is given for $\mathrm{X}=\mathrm{F}$ (ca. $-3200 \mathrm{kcal} \mathrm{mol}^{-1}$ ) and the smallest value is given for $\mathrm{X}=\mathrm{I}$ (ca. $-2500 \mathrm{kcal} \mathrm{mol}^{-1}$ ). This demonstrates that the iodine complex has the weakest $\mathrm{B}-\mathrm{B}$ and $\mathrm{B}-\mathrm{I}$ interactions, while the bonds in $\mathrm{B}_{12} \mathrm{Cl}_{7}{ }^{-}$and $\mathrm{B}_{12} \mathrm{Br}_{7}{ }^{-}$ are slightly weaker than those in the fluorine complex. This trend can be also understood by the term of orbital interactions, $E_{\text {orb }}$. For $\mathrm{X}=\mathrm{F}$, the total energy has the largest value of $E_{\text {orb }}$, while $\mathrm{X}=\mathrm{I}$ has the smallest values, and the difference was about $1000 \mathrm{kcal} \mathrm{mol}^{-1}$. Thus, we observe a stronger covalent characteristic in $\mathrm{B}_{12} \mathrm{~F}_{7}^{-}$than in $\mathrm{B}_{12} \mathrm{I}_{7}^{-}$. Talking about the absolute values, both $E_{\text {Pauli }}$ and $E_{\text {elstat }}$ followed the same trend: $\mathrm{F}>\mathrm{Cl}>\mathrm{Br}>\mathrm{I}$. To have a clearer profile, we focus on the energy difference, $\Delta E($ open - close $)$, for each contribution of the total interactions. In general, the open structures are stabilized by Pauli repulsions (negative values) and are destabilized by $\Delta E_{\text {elstat }}$ and $\Delta E_{\text {orb }}$ (positive values). Since the absolute values of $\Delta E_{\text {Pauli }}$ are much bigger than those of $E_{\text {elstat }}$, the summation of these two terms gives negative values which are comparable to the absolute vales of $\Delta E_{\text {orb. }}$ In short, we

TABLE II. The energy decomposition analysis (EDA) at the $\mathrm{PBE}$ /ZORA/TZ2P level of theory for open- and close $-\mathrm{B}_{12} \mathrm{X}_{7}{ }^{-}(\mathrm{X}=\mathrm{F}, \mathrm{Cl}$, $\mathrm{Br}$ and I). All the values are given in $\mathrm{kcal} \mathrm{mol}^{-1}$.

\begin{tabular}{lrrrrr}
\hline \hline Cluster & \multicolumn{1}{c}{$E_{\text {Pauli }}$} & \multicolumn{1}{c}{$E_{\text {elstat }}$} & $E_{\text {Pauli }}+E_{\text {elstat }}$ & \multicolumn{1}{c}{$E_{\text {orb }}$} & \multicolumn{1}{c}{$E_{\text {total }}$} \\
\hline $\mathrm{B}_{12} \mathrm{~F}_{7}{ }^{-}$ & & & & & \\
open & 13654.51 & -3016.06 & 10638.46 & -13828.08 & -3189.62 \\
close & 14378.55 & -3279.99 & 11098.57 & -14308.63 & -3210.05 \\
$\Delta E$ & -724.04 & 263.93 & -460.11 & 480.55 & 20.43 \\
\hline $\mathrm{B}_{12} \mathrm{Cl}_{7}^{-}$ & & & & & \\
open & 13129.50 & -2972.65 & 10156.85 & -12892.40 & -2735.55 \\
close & 13721.34 & -3230.27 & 10491.07 & -13240.94 & -2749.86 \\
$\Delta E$ & -591.84 & 257.62 & -334.22 & 348.54 & 14.31 \\
\hline $\mathrm{B}_{12} \mathrm{Br}_{7}^{-}$ & & & & & \\
open & 12800.46 & -2951.15 & 9849.32 & -12456.66 & -2607.35 \\
close & 13363.83 & -3204.90 & 10158.93 & -12779.53 & -2620.60 \\
$\Delta E$ & -563.37 & 253.75 & -309.61 & 322.87 & 13.25 \\
\hline $\mathrm{B}_{12} \mathrm{I}_{7}^{-}$ & & & & & \\
open & 12417.68 & -2879.42 & 9538.25 & -12006.46 & -2468.21 \\
close & 12948.99 & -3129.50 & 9819.49 & -12298.65 & -2479.16 \\
$\Delta E$ & -531.31 & 250.08 & -281.24 & 292.19 & 10.95 \\
\hline \hline
\end{tabular}


conclude that the open structures are stabilized by static interactions $\left(\Delta E_{\text {stat }}=E_{\text {Pauli }}+E_{\text {elstat }}\right)$ and are destabilized by $\Delta E_{\text {orb }}$. Changing from $\mathrm{F}$ to I, we find that both the $\Delta E_{\text {stat }}$ stability and the $\Delta E_{\text {orb }}$ destability decrease. However, they decrease with different rates. For example, $\Delta E_{\text {stat }}$ is $-460.1 \mathrm{kcal} \mathrm{mol}^{-1}$ in the case of $\mathrm{B}_{12} \mathrm{~F}_{7}^{-}$and it increases to $-281.2 \mathrm{kcal} \mathrm{mol}^{-1}$ for $\mathrm{B}_{12} \mathrm{I}_{7}^{-}$. Thus, the stability decreases to $177.9 \mathrm{kcal} \mathrm{mol}^{-1}$. On the other hand, $\Delta E_{\text {orb }}$ is $480.6 \mathrm{kcal} \mathrm{mol}^{-1}$ in the case of $\mathrm{B}_{12} \mathrm{~F}_{7}^{-}$and it decreases to $292.2 \mathrm{kcal} \mathrm{mol}^{-1}$ for $\mathrm{B}_{12} \mathrm{I}_{7}^{-}$. The corresponding destability decreases to $188.4 \mathrm{kcal} \mathrm{mol}^{-1}$. Therefore, the difference between the stability from $\Delta E_{\text {stat }}$ and the destability from $\Delta E_{\text {orb }}$ is $10.5 \mathrm{kcal} \mathrm{mol}^{-1}$ when changing from $\mathrm{F}$ to I. As such, $\Delta E$ (open - close) is $20.4 \mathrm{kcal} \mathrm{mol}^{-1}$ for $\mathrm{B}_{12} \mathrm{~F}_{7}^{-}$and it is $11.0 \mathrm{kcal} \mathrm{mol}{ }^{-1}$ for $\mathrm{B}_{12} \mathrm{I}_{7}^{-}$.

\section{CONCLUSIONS}

In this study, we investigated the effects of different halogen atoms ( $\mathrm{F}$ to $\mathrm{I}$ ) on the opening of the icosahedral $\mathrm{B}_{12}$ cage by means of DFT calculations. We first investigated the effects on the geometric parameters as well as the IR spectra by changing the dopants from F to I. Subsequently, we computed the Gibbs free energy differences $(\Delta G)$ between the open- and close- $\mathrm{B}_{12} \mathrm{I}_{7}{ }^{-}$clusters, and the electronic energy contributions were studied by the energy decompositions analysis (EDA). We found that the halogen atoms do not have significant effects on the geometry of the structures. Moreover, the computed IR spectra showed similar representative peaks for all halogen atoms. Interestingly, while increasing the mass of the halogen atoms, we found a blue-shift in the IR spectra. The largest shift found was for the peaks $\mathrm{B}^{\prime}$ (the vibrational mode of the icosahedral-like boron atoms) of open- $\mathrm{B}_{12} \mathrm{X}_{7}^{-}$which was about $200 \mathrm{~cm}^{-1}$ in the case of iodine substitution. Finally, we compared the Gibbs free energies at different temperatures for different halogen atoms. It was shown that the open structures of $\mathrm{B}_{12} \mathrm{X}_{7}^{-}$became more stable over the close structures when heavier halogen atoms were present. EDA results show that this general trend is because the stability from static interactions $\left(\Delta E_{\text {stat }}\right)$ and the destability from orbital interactions $\left(\Delta E_{\text {orb }}\right)$ decrease in different rates.

\section{SUPPLEMENTARY MATERIAL}

See supplementary material for geometric parameters, natural bond orbital (NBO) charges, and low-lying isomers.

\section{ACKNOWLEDGMENTS}

We thank Chemical Design Laboratory of National Demonstration Center of Chemistry and Chemical Engineering Experimental Teaching, Beijing Institute of Petrochemical Technology for allocation of computational resources.

The authors declare no competing financial interest.
${ }^{1}$ T. Peymann, C. B. Knobler, S. I. Khan, and M. F. Hawthorne, Angew. Chem., Int. Ed. 40, 1664-1667 (2001).

${ }^{2}$ E. D. Jemmis, J. Am. Chem. Soc. 104, 7017-7020 (1982).

${ }^{3}$ F. A. Gomez, S. E. Johnson, C. B. Knobler, and M. F. Hawthorne, Inorg. Chem. 31, 3558-3567 (1992).

${ }^{4}$ J. Kreuter, R. Alyautdin, D. Kharkevich, and A. Ivanov, Brain Res. 674, 171-174 (1995).

${ }^{5}$ M. J. Hardie, J. Chem. Crystallogr. 37, 69-80 (2007).

${ }^{6}$ K. Binnemans, Chem. Rev. 105, 4148-4204 (2005).

${ }^{7}$ I. Krossing and I. Raabe, Angew. Chem., Int. Ed. 43, 2066-2090 (2004).

${ }^{8}$ R. E. Williams, Chem. Rev. 92, 177-207 (1992).

${ }^{9}$ P. Farràs, N. Vankova, L. L. Zeonjuk, J. Warneke, T. Dülcks, T. Heine, C. Viñas, F. Teixidor, and D. Gabel, Chem. - Eur. J. 18, 13208-13212 (2012).

${ }^{10}$ L. L. Zeonjuk, N. Vankova, C. Knapp, and D. G. T. Heine, Phys. Chem. Chem. Phys. 15, 10358-10366 (2013).

${ }^{11}$ L. Liu, E. Osorio, and T. Heine, Phys. Chem. Chem. Phys. 18, 18336-18341 (2016).

${ }^{12}$ M. A. Fox and K. Wade, Pure Appl. Chem. 75, 1315-1323 (2003).

${ }^{13}$ A. P. Sergeeva, I. A. Popov, Z. A. Piazza, W. L. Li, C. Romanescu, L. S. Wang, and B. I. Alexander, Acc. Chem. Res. 47, 1349-1358 (2014).

${ }^{14}$ L. S. Wang, Int. Rev. Phys. Chem. 35, 69-142 (2016).

${ }^{15}$ L. Liu and B. Lukose, J. Apl. Theol. 1, 5-8 (2016).

${ }^{16}$ H. J. Zhai, Y. F. Zhao, W. L. Li, Q. Chen, H. Bai, H. S. Hu, Z. A. Piazza, W. J. Tian, H. G. Lu, Y. B. Wu, Y. W. Mu, G. F. Wei, Z. P. Liu, J. Li, S. D. Li, and L. S. Wang, Nat. Chem. 6, 727-731 (2014).

${ }^{17}$ X.-M. Luo, T. Jian, L.-J. Cheng, W.-L. Li, Q. Chen, R. Li, H.-J. Zhai, Si-D. Li, A. I. Boldyrev, J. Li, and L.-S. Wang, Chem. Phys. Lett. 683, 336-341 (2017).

${ }^{18}$ L. Liu, E. Osorio, and T. Heine, Chem. - Asian J. 11, 3220-3224 (2016).

${ }^{19}$ J. Warneke, T. Dülcks, C. Knapp, and D. Gabel, Phys. Chem. Chem. Phys. 13, 5712-5721 (2011).

${ }^{20}$ M. R. Fagiania, L. L. Zeonjukc, T. K. Esser, D. Gabel, T. Heine, K. R. Asmis, and J. Warneke, Chem. Phys. Lett. 625, 48-52 (2015).

${ }^{21}$ J. K. Olson and A. I. Boldyrev, J. Phys. Chem. A 117, 1614-1620 (2013).

${ }^{22}$ M. J. Frisch, G. W. Trucks, H. B. Schlegel, G. E. Scuseria, M. A. Robb, J. R. Cheeseman, G. Scalmani, V. Barone, B. Mennucci, G. A. Petersson, H. Nakatsuji, M. Caricato, X. Li, H. P. Hratchian, A. F. Izmaylov, J. Bloino, G. Zheng, J. L. Sonnenberg, M. Hada, M. Ehara, K. Toyota, R. Fukuda, J. Hasegawa, M. Ishida, T. Nakajima, Y. Honda, O. Kitao, H. Nakai, T. Vreven, J. A. Montgomery, Jr., J. E. Peralta, F. Ogliaro, M. Bearpark, J. J. Heyd, E. Brothers, K. N. Kudin, V. N. Staroverov, R. Kobayashi, J. Normand, K. Raghavachari, A. Rendell, J. C. Burant, S. S. Iyengar, J. Tomasi, M. Cossi, N. Rega, J. M. Millam, M. Klene, J. E. Knox, J. B. Cross, V. Bakken, C. Adamo, J. Jaramillo, R. Gomperts, R. E. Stratmann, O. Yazyev, A. J. Austin, R. Cammi, C. Pomelli, J. W. Ochterski, R. L. Martin, K. Morokuma, V. G. Zakrzewski, G. A. Voth, P. Salvador, J. J. Dannenberg, S. Dapprich, A. D. Daniels, Ö. Farkas, J. B. Foresman, J. V. Ortiz, J. Cioslowski, and D. J. Fox, Gaussian 09, Revision A.02, Gaussian, Inc., Wallingford, CT, 2009.

${ }^{23}$ C. Adamo and V. Barone, J. Chem. Phys. 110, 6158-6169 (1999).

${ }^{24}$ F. Weigend, R. Ahlrichs, and F. K. Gmbh, Phys. Chem. Chem. Phys. 7, 3297-3305 (2005).

${ }^{25}$ P. J. Hay and W. R. Wadt, J. Chem. Phys. 82, 299-310 (1985).

${ }^{26}$ L. Liu, D. Moreno, E. Osorio, A. C. Castro, S. Pan, P. K. Chattaraj, T. Heine, and G. Merino, RSC Adv. 6, 27177-27182 (2016).

${ }^{27}$ M. von Hopffgarten and G. Frenking, Wiley Interdiscip. Rev.: Comput. Mol. Sci. 2, 43-62 (2012).

${ }^{28}$ E. Van Lenthe and E. J. Baerends, J. Comput. Chem. 24, 1142-1156 (2003).

${ }^{29}$ E. Van Lenthe, A. Ehlers, E. Baerends, E. Van Lenthe, A. Ehlers, and E. Baerends, J. Chem. Phys. 110, 8943-8953 (1999).

${ }^{30} \mathrm{G}$. te Velde, F. M. Bickelhaupt, E. J. Baerends, C. F. Guerra, S. J. A. van Gisbergen, J. G. Snijders, and T. Ziegler, J. Comput. Chem. 22, 931-967 (2001). 